\title{
Quality of Life of Patients with Leukemia Undergoing Chemotherapy
}

\author{
Athar Gamal El- Nagar ${ }^{1}$, Abeer Elshatby Mohamed ${ }^{2}$, Naglaa Fathalla El- Sayed ${ }^{3}$, Heba Elsayed Khattab ${ }^{4}$. \\ 1. Demonstrator of Medical Surgical Nursing Department, Faculty of nursing, Alexandria University, Egypt. \\ 2. Professor. Medical Surgical Nursing Department, Faculty of nursing, Alexandria University, Egypt. \\ 3. Assistant Professor Medical Surgical Nursing Department, Faculty of nursing, Alexandria University, Egypt. \\ 4. Lecturer Medical Surgical Nursing Department, Faculty of nursing, Alexandria University, Egypt.
}

\begin{abstract}
:
Leukemia is a stem cell disorder characterized by a malignant neoplastic proliferation and accumulation of immature hematopoietic cells in the bone marrow. Aim of the study: assess quality of life of patients with leukemia undergoing chemotherapy. Subjects \& Method: A descriptive design was conducted at the Oncology Department and Hematology Unit at Alexandria Main University Hospital, Egypt. Subjects: a convenient sample of 150 adult patients diagnosed with leukemia who had received at least 2 cycles of chemotherapy. Tools: Tool I: Leukemic Patient's Structured Interview Schedule: It was included two parts: Part (I) Socio-demographic Data. Part (II) Clinical Data. Tool II: Leukemic patients' Health related Quality of Life Questionnaire: It was consisted of 8 domains \& included 36 statements. Results: $51.3 \%$ have poor general health; there was no correlation between the QOL and socio-demographic variables, while there was no statistical significant relation between other clinical data of the studied patients and overall QOL percent score Conclusion: more than half patients with leukemia who received chemotherapy had poor QOL which have negative impact on patient's physical, psychological, social life, and spiritual life. Recommendation: Pre and in-services training programs need to be developed for Chemotherapeutic Patients and nurses working with leukemia patients receiving chemotherapy.
\end{abstract}

\section{Keywords: Chemotherapy, Leukemia \& Quality of life.}

\section{Introduction:}

Leukemia is a stem cell disorder characterized by a malignant neoplastic proliferation and accumulation of immature hematopoietic cells in the bone marrow, which is a malignancy disease that affecting the blood and blood-tissues, lymphatic system, and spleen (Porcu et al., 2016). The leukemia described as "white blood cells" which is a neoplastic procreation of single type of blood cell, in a white blood cell. Leukocytosis it defined as elaboration of white blood cells number, which is a usual response to infection. While, when leukocytosis accelerated without reason, then it means malignancy (Kebriaei, de Lima, Estey \& Champlin, 2015).

A number of major contributing factors increase the risk of developing leukemia such as genetics are playing an important role only for a small proportion of cases (Kasim et al., 2015). There are some identified chromosomal anomalies related to leukemia, For example the Down syndrome (Stiller, Chessells \& Fitchett, 2014), Klinefelter syndrome, ataxia telangiectasia, Bloom syndrome and Fanconi anemia are chromosomal syndromes causing predisposition to leukemia (Robison, 2012) . In the largest population-based study evidence for a strong familial clustering for multiple myeloma, Chronic Lymphocyte Leukemia (CLL), Non-Hodgkin Lymphoma (NHL) was provided (Altieri et al., 2016).
Leukemia produces signs and symptoms may vary according the type of leukemia and the different stages and if it acute onset or gradually. The most common signs and symptoms are fever, bruising, bone pain, weight loss, malaise, fatigue, bleeding, epistaxis and splenomegaly. In acute phase starting of symptoms is commonly quite abrupt and includes severe infection and bleeding, neutropenia and thrombocytopenia are common. All results detoriated immune system, anemia, and exaggerated bleeding tendencies. Disseminated intravascular coagulation (DIC) it occur in $10 \%$ of patients, because of thrombocytopenia. Usual manifestations include: anemia, increased infection and mouth sores (Redaelli et al., 2013).

Leukemia diagnosed initially by a physical examination of suspected individuals; the initial investigation to determine abnormalities is blood cell results to determine if there are increased numbers of blasts in the blood or bone marrow, while, a bone marrow biopsy it fit out the definitive diagnosis. In chronic myeloid leukemia the diagnosis determine with blood studies that show a white blood cell count of 20,000 to 60,000 with elevated in mature granulocytes. Basophils and eosinophils often appear a mild increase. Bone marrow biopsy with cytogenic studies fit out definitive diagnosis, markedly with a discovery of the Philadelphia (Ph1) chromosome (Hallek, 2015). 
Management of leukemia includes chemotherapy, targeted therapy, interferon therapy, radiation, surgery and stem cell transplantation. Chemotherapy is the main treatment for patients with acute AML (Larson et al., 2012) treatment will typically depend upon the type of leukemia, the patient's age and health status, as well as whether or not the leukemia cells have spread to the cerebrospinal fluid. The genetic changes or specific characteristics of the leukemia cells as determined in the laboratory can also determine the type of treatment that may be most appropriate (Hallek et al., 2015).

Chemotherapy is primarily aimed to prevent replication of malignant cells and to treat systemic disease, such as leukemia or other metastasized cancers. Chemotherapy is used to cure, control, or provide palliation, so medications are chosen based on the realistic goal for the individual patient cells that are actively proliferating are the most sensitive to chemotherapy (Schirrmacher 2019). Cells that are not dividing but have the potential for proliferation are not destroyed by chemotherapy, so repeated cycles of therapy are required in order to kill these cells as they become activated. Chemotherapy has negative consequences which effect on quality of life in patient receiving it (Huang et al., 2017).

Quality of life is defined as a concept of economics, sociology and political science which encompasses an individual's spiritual (emotional), social and physical well-being. This concept originated in Western Europe in the middle of the 20th century when attempts were made to identify the correlation of society's traditional material interests and newly evolved needs as compared to the potential of society ( El-desouky et al., 2017).

WHO defines QOL as 'individuals' perceptions of their position in life in the context of the culture and value systems in which they live and in relation to their goals, expectations, standards and concerns". (WHO 2012).

Quality of nursing care is the degree of which health care for patient increases the likelihood of desired outcome and consistent with current professional knowledge (Mains, \& Andaleeb, 2016). QOL is influenced by an individual's physical and mental health, the degree of independency, the social relationship with the environment, and other factors. The goal of much care in chronic illness is to improve QOL. Regarding assessment of quality of life the nurse can use different methods that measure health status aspects as physical functioning, role limitations due to physical health, role limitations due to emotional problems, energy/fatigue, psychological well-being, social functioning, pain assessment and general health. These aspects can be used as indicators to measure any improvement or deterioration in health status (WHO 2012).

\section{Significance of the study}

Leukemia is developed all over the world, it accounts for almost $10 \%$ of all malignancies diagnosed each year in the United States (US), with 40.000 to 50.000 new diagnoses annually (Ghazawi et al., 2019). In 2018, leukemia was reported as the $14^{\text {th }}$ most common cancer and the $11^{\text {th }}$ leading cause of mortality from cancer worldwide. In 2018, approximately 60,300 male and female $(32,460$ male and 27,840 female) in the US were recognized with leukemia, and 21,840 drop of the disease (National Cancer Institute [NCI]. At Egypt the rate was estimated that $119.7 / 100,000$ males and 107.3/100,000 of females in 2014 (DeSantis et al., 2014).

Despite the fact that leukemia is the most common malignancy among the people under the age of 20 years, most leukemia cases occur in the elderly, so that the highest incidence of this disease is observed in the age group of 65 and older (Curado et al., 2017).

Therefore, it is necessary for the nurses to perform frequent assessment of QOL of leukemia patients throughout receiving of chemotherapy and to utilize the results of assessments in interventions in order to measure and improve the quality of patient's life, achieve high quality patient care, shortening hospitalization and return to normal life early. So, this study aimed to assess quality of life of patients with leukemia undergoing chemotherapy

\section{Aim of the study}

Assess the quality of life of patients with leukemia undergoing chemotherapy

\section{Research question:}

What is the quality of life of patients with leukemia undergoing chemotherapy?

\section{Materials and Method \\ Design:}

A descriptive research design was utilized for this study.

Setting:

The present study was conducted at the Oncology Department and Hematology Unit at Alexandria Main University Hospital, Egypt. The Hematology Unit is divided into 2 wards for males and 3 for females. Each male ward contains 8 beds. Regarding female wards one contains 8 beds while the other 2 wards contain 4 beds. The Oncology Department contains 7 beds. 


\section{Subjects:}

A convenience sample of 150 adult patients admitted to the above mentioned settings diagnosed with leukemia who have received at least 2 cycles of chemotherapy, will included in the study.

The study sample will be estimated based on Epi info -7 program using the following parameters;

1. Population size: $400 /$ year

2. Expected frequency: $50 \%$

3. Acceptable error: $10 \%$

4. Confidence coefficient: $99 \%$

5. Minimum sample size: 150

Inclusion criteria:

- Adult male\& female patients (aged 21 - 60 years) (Hutter, 2010).

- After second chemotherapy cycle.

- Free from associated chronic diseases or other cancer site(s).

- Able to communicate verbally.

Tools of the study:

Two tools were used in this study to obtain necessary data.

Tool I: Leukemic patients Structured Interview Schedule:

This tool developed by the researcher after review of the relevant literature to elicit the data about patient's characteristics. It was included two parts:

Part (I) Socio-demographic Data: includes age, sex, and level of education, occupation, marital status, and area of residence.

Part (II) Clinical Data: includes past medical history; onset of disease, signs\& symptoms of disease, time of seeking medical help, family history and therapy regarding frequency and number of chemotherapy cycles.

Tool II: Leukemic patients Health related Quality of Life Short form Questionnaire:

This tool was developed by (Ware JE at 2014 ) and it was updated at by the same author at 2014 . It is proved to be a reliable and valid instrument for assessing the quality of life. It was adopted to obtain self-report health-related quality-of-life for people with leukemia. It was consisted of 8 domains \& included 36 statements:

1. $1^{\text {st }}$ domain: Physical functioning includes 10 statements: ability to function physically and daily of living activities.

2. $2^{\text {nd }}$ domain: Role limitations due to physical health include 4 statements regarding the activities levels.

3. $3^{\text {rd }}$ domain: Role limitations due to emotional problems include 3 statements regarding the anxiety or depression.

4. $4^{\text {th }}$ domain: Energy/fatigue includes 4 statements for fatigue level related to daily of living activities.

5. $5^{\text {th }}$ domain: Psychological well-being includes5 statements for self-image, fears and anxiety.

6. $6^{\text {th }}$ domain: social functioning includes 2 statements regarding the interpersonal relationship with family and others.

7. $7^{\text {th }}$ domain: Pain assessment includes 2 statements for pain severity and interference with activities.

8. $8^{\text {th }}$ domain: General health includes 6 statements related to health status and expectation.

Scoring System:

Each positively oriented response toward quality of life domains was scored on 5-point likert scale from (5-1). A score 5 assigned to the item response choice very much, (4) was coded as quite a bit, (3) was coded as somewhat, (2) was coded as a little bit and (1) for not at all. While each negatively response toward d health problems and unhealthy behaviors toward quality of life domains was scored from (1-5). A one for very much and (5) for not at all.

Total score was ranged from 36 to 180 , the total quality of life score was summed, converted into percent score and judged as follows: scoring of less than $50 \%$ were considered as "poor quality of life", while scoring from 50 to $75 \%$ were considered as "fair quality of life" and scoring from 76 to $100 \%$ were considered as "good quality of life" (Ware et al., 2014).

\section{Method}

Written Approval:

Official approval was obtained from ethical committee, Faculty of Nursing, Alexandria University to carry out the study. Official permission was granted from the authorities and head of the Oncology Department and Hematology Unit of Alexandria Main University Hospital after explication the study aim.

Tool development:

Health related Quality of Life questionnaire (Tool II) was adopted and translated into Arabic language by the researcher after review of relevant literature and according to jury.

Testing of content validity:

The tools were submitted to jury members of five experts in the field of Medical-Surgical nursing, Faculty of Nursing (Alexandria University), to assure the validity, completeness of the content and purity of items and appropriateness of translations. Every jury member was informed about the aim and method of the study. Comments and suggestions of jury were considered, and the tools were modified accordingly. 


\section{Reliability testing:}

Tool II (Health related Quality of Life Short Form questionnaire) was tested for its reliability on a sample of 10 subjects using Alpha Cronbach's statistical test for internal consistency of tool items. The data was analyzed; the correlation coefficient was (0.9).

\section{Pilot study}

A pilot study was carried out on $10 \%$ (15) patients in the hematology unit to ascertain the clarity and applicability of the study tools and to identify obstacles that may be faced during data collection and then necessary modifications were done. These patients were excluded from the actual study subjects.

\section{Data collection:}

\section{Steps of the study:}

1. After securing administrative approval, data collection was initiated covering a period of 3 months from October 2019 to the end of December 2019.

2. The total subjects consisted of 150 adult patients received chemotherapy. All patients met the included criteria of subjects' selection in the study.

3. The study aim was explained to every patient by the researcher. Each patient was interviewed individually by the researcher in the morning shift once after the $2^{\text {nd }}$ chemotherapy cycles at the inpatient unit; the interview took 30 to 45 minutes to collect the needed data related to socio-demographic and assess quality of life among leukemia patients by using the developed tool.

\section{Ethical Considerations}

- Written approval was obtained from the head of both departments to collect the data after explanation of the aim of the study.

- Patients willing to participate in the study.

- Written informed patient consents were obtained before data collection and after explanation of the study aim.

- Anonymity, confidentiality and privacy were asserted.

- The patients were informed that their participation in the study is voluntary and they can withdraw at any time.

\section{Statistical Analysis}

After data collection, it was coded and transferred into a specially designed format so as to be suitable for computer feeding. Following data entry , checking and verification processes were carried out to avoid errors during data entry Statistical package for Social Sciences (SPSS) version 20 for windows was used for data analysis (Armonk, NY: IBM Corp) The following statistical tests were used in the study:

A. Descriptive statistics: as Count and percentage, Minimum, maximum, Arithmetic mean (X), and Standard deviation (SD).

B. Analytical statistics: as Cronbach's Alpha, Graphical presentation, Chi-square test, and Monte Carlo correction

\section{Results:}

Table (1): Frequency distribution of the studied patients according to socio- demographic characteristics $(\mathbf{n}=\mathbf{1 5 0})$

\begin{tabular}{|l|c|c|}
\hline \multicolumn{1}{|c|}{ Socio demographic characteristics } & No. & \% \\
\hline Age & & 35.3 \\
\hline 21 to $<30$ & 53 & 10.7 \\
\hline 30 to $<40$ & 16 & 13.3 \\
\hline 40 to $<50$ & 20 & 40.7 \\
\hline 50 to 60 & 61 & \\
\hline Mean \pm SD. & \multicolumn{1}{|c|}{3} \\
\hline Sex & $97.63 \pm 9.583$ \\
\hline Male & 53 & 35.3 \\
\hline Female & & \\
\hline Residence & 114 & 76.0 \\
\hline Urban & 36 & 24.0 \\
\hline Rural & & \\
\hline Level of education & 61 & 40.7 \\
\hline Illiterate & 46 & 30.7 \\
\hline Read and Write & 4 & 2.7 \\
\hline Primary & & \\
\hline
\end{tabular}




\begin{tabular}{|l|c|c|}
\hline \multicolumn{1}{|c|}{ Socio demographic characteristics } & No. & \% \\
\hline Secondary & 26 & 17.3 \\
\hline University & 13 & 8.7 \\
\hline Occupation & & 17.3 \\
\hline Professional work & 26 & 49.4 \\
\hline Manual work & 74 & 31.3 \\
\hline Not worker & 47 & 2.0 \\
\hline Others & 3 & 21.3 \\
\hline Marital status & 32 & 68.0 \\
\hline Single & 102 & 0.0 \\
\hline Married & 0 & 10.7 \\
\hline Divorced & 16 & \\
\hline Widow & & 81.3 \\
\hline Economic status & 122 & 18.7 \\
\hline Less than enough & 28 & \\
\hline Enough & \multicolumn{2}{|c|}{} \\
\hline
\end{tabular}

Table (2): Mean, Standard deviations and test of significance among the studied patient's quality of life domains $(\mathbf{n}=\mathbf{1 5 0})$

\begin{tabular}{|c|c|c|c|c|c|c|c|}
\hline \multirow{2}{*}{ Quality of life domains } & \multicolumn{2}{|c|}{$<50 \%$ Poor } & \multicolumn{2}{|c|}{ 50-75\% Fair } & \multicolumn{2}{|c|}{$>75$ Good } & \multirow{2}{*}{$\begin{array}{l}\text { Min-Max } \\
\text { Mean } \pm \text { SD }\end{array}$} \\
\hline & No. & $\%$ & No. & $\%$ & No. & $\%$ & \\
\hline General health & 88 & 58.7 & 61 & 40.6 & 1 & 0.7 & $\begin{array}{c}0.0-79.17 \\
41.69 \pm 19.81\end{array}$ \\
\hline Pain assessment & 102 & 68.0 & 45 & 30.0 & 3 & 2.0 & $\begin{array}{c}0.0-100.0 \\
34.17 \pm 24.18 \\
\end{array}$ \\
\hline Social Functioning & 73 & 48.7 & 72 & 48.0 & 5 & 3.3 & $\begin{array}{c}0.0-100.0 \\
38.0 \pm 25.98\end{array}$ \\
\hline Psychological well-being & 60 & 40.0 & 73 & 48.7 & 17 & 11.3 & $\begin{array}{c}0.0-100.0 \\
48.10 \pm 25.05\end{array}$ \\
\hline Energy / Fatigue & 45 & 30.0 & 103 & 68.7 & 2 & 1.3 & $\begin{array}{c}0.0-87.50 \\
48.83 \pm 20.90 \\
\end{array}$ \\
\hline $\begin{array}{l}\text { Role limitation due to } \\
\text { emotional problems }\end{array}$ & 62 & 41.3 & 83 & 55.3 & 5 & 3.3 & $\begin{array}{c}0.0-83.33 \\
43.61 \pm 22.69\end{array}$ \\
\hline $\begin{array}{l}\text { Role limitation due to } \\
\text { physical health problems }\end{array}$ & 64 & 42.7 & 79 & 52.7 & 7 & 4.7 & $\begin{array}{c}0.0-87.50 \\
45.25 \pm 23.11 \\
\end{array}$ \\
\hline Physical Functioning & 64 & 42.7 & 45 & 30.0 & 41 & 27.3 & $\begin{array}{c}0.0-100.0 \\
47.27 \pm 35.87 \\
\end{array}$ \\
\hline $\begin{array}{l}\text { Overall percent score } \\
\text { quality of life domains }\end{array}$ & 87 & $\mathbf{5 8 . 0}$ & 60 & 40.0 & 3 & 2.0 & $\begin{array}{c}\text { O.0- } 84.03 \\
44.86 \pm 20.28\end{array}$ \\
\hline
\end{tabular}

Table (3): Relationship between socio-demographic characteristics of the studied patients and overall QOL domains percent score. $(n=150)$

\begin{tabular}{|c|c|c|c|c|c|c|c|c|}
\hline \multirow{3}{*}{ Socio demographic data } & \multicolumn{6}{|c|}{$\begin{array}{c}\text { Overall quality of life } \\
\end{array}$} & \multirow{3}{*}{$\chi^{2}$} & \multirow{3}{*}{${ }^{\mathrm{MC}} \mathbf{p}$} \\
\hline & \multicolumn{2}{|c|}{ Poor(n= 87) } & \multicolumn{2}{|c|}{ Fair $(\mathbf{n}=60)$} & \multicolumn{2}{|c|}{$\operatorname{Good}(n=3)$} & & \\
\hline & No. & $\%$ & No. & $\%$ & No. & $\%$ & & \\
\hline \multicolumn{9}{|l|}{ Age } \\
\hline 21 to $<30$ & 31 & 35.6 & 20 & 33.3 & 2 & 66.7 & \multirow{4}{*}{12.881} & \multirow{4}{*}{$0.024 *$} \\
\hline 30 to $<40$ & 11 & 12.6 & 5 & 8.3 & 0 & 0.0 & & \\
\hline 40 to $<50$ & 12 & 13.8 & 8 & 13.3 & 0 & 0.0 & & \\
\hline 50 to 60 & 33 & 37.9 & 27 & 45.0 & 1 & 33.3 & & \\
\hline \multicolumn{9}{|l|}{ Sex } \\
\hline Male & 55 & 63.2 & 41 & 68.3 & 1 & 33.3 & \multirow{2}{*}{1.790} & \multirow{2}{*}{0.421} \\
\hline Female & 32 & 36.8 & 19 & 31.7 & 2 & 66.7 & & \\
\hline \multicolumn{9}{|l|}{ Residence } \\
\hline Urban & 66 & $\overline{75.9}$ & 46 & 76.7 & 2 & 66.7 & \multirow{2}{*}{0.536} & \multirow{2}{*}{0.937} \\
\hline Rural & 21 & 24.1 & 14 & 23.3 & 1 & 33.3 & & \\
\hline
\end{tabular}




\begin{tabular}{|c|c|c|c|c|c|c|c|c|}
\hline \multirow{3}{*}{ Socio demographic data } & \multicolumn{6}{|c|}{ Overall quality of life } & \multirow{3}{*}{$\chi^{2}$} & \multirow{3}{*}{${ }^{\mathrm{MC}} \mathbf{p}$} \\
\hline & \multicolumn{2}{|c|}{$\operatorname{Poor}(\mathbf{n}=87)$} & \multicolumn{2}{|c|}{ Fair(n=60) } & \multicolumn{2}{|c|}{ Good(n=3) } & & \\
\hline & No. & $\%$ & No. & $\%$ & No. & $\%$ & & \\
\hline Level of education & & & & & & & & \\
\hline Illiterate & 30 & 34.5 & 16 & 26.7 & 0 & 0.0 & \multirow{5}{*}{12.552} & \multirow{5}{*}{0.085} \\
\hline Read and Write & 37 & 42.5 & 24 & 40.0 & 0 & 0.0 & & \\
\hline Primary & 3 & 3.4 & 1 & 1.7 & 0 & 0.0 & & \\
\hline Secondary & 10 & 11.5 & 13 & 21.7 & 3 & 100.0 & & \\
\hline University & 7 & 8.0 & 6 & 10.0 & 0 & 0.0 & & \\
\hline \multicolumn{9}{|l|}{ Occupation } \\
\hline Professional work & 15 & 17.2 & 11 & 18.3 & 0 & 0.0 & \multirow{4}{*}{2.935} & \multirow{4}{*}{0.999} \\
\hline Manual work & 42 & 48.2 & 30 & 49.0 & 1 & 66.6 & & \\
\hline Not worker & 28 & 32.2 & 18 & 30.0 & 2 & 33.4 & & \\
\hline Others & 2 & 2.3 & 1 & 1.7 & 0 & 0.0 & & \\
\hline \multicolumn{9}{|l|}{ Social status } \\
\hline Single & 16 & 18.4 & 15 & 25.0 & 1 & 33.3 & \multirow{3}{*}{3.092} & \multirow{3}{*}{0.511} \\
\hline Married & 59 & 67.8 & 41 & 68.3 & 2 & 66.7 & & \\
\hline Widow & 12 & 13.8 & 4 & 6.7 & 0 & 0.0 & & \\
\hline \multicolumn{9}{|l|}{ Economic status } \\
\hline Less than enough & 68 & 78.2 & 51 & 85.0 & 3 & 100.0 & \multirow{2}{*}{1.268} & \multirow{2}{*}{0.500} \\
\hline Enough & 19 & 21.8 & 9 & 15.0 & 0 & 0.0 & & \\
\hline
\end{tabular}

*: Statistically significant at $p \leq 0.05$

Table (4): Relationship between clinical data of the studied patients and overall quality of life (QoL) domains percent score $(\mathbf{n}=\mathbf{1 5 0})$

\begin{tabular}{|c|c|c|c|c|c|c|c|c|}
\hline \multirow{3}{*}{ Clinical data } & \multicolumn{6}{|c|}{ Overall quality of life } & \multirow{3}{*}{$\chi^{2}$} & \multirow{3}{*}{${ }^{\mathrm{MC}} \mathbf{p}$} \\
\hline & \multicolumn{2}{|c|}{$\begin{array}{c}\text { Poor } \\
(\mathbf{n}=87)\end{array}$} & \multicolumn{2}{|c|}{$\begin{array}{c}\text { Fair } \\
(\mathbf{n}=60)\end{array}$} & \multicolumn{2}{|c|}{$\begin{array}{c}\text { Good } \\
(\mathbf{n}=3)\end{array}$} & & \\
\hline & No. & $\%$ & No. & $\%$ & No. & $\%$ & & \\
\hline \multicolumn{9}{|c|}{ Patient's past medical history } \\
\hline Onset of disease & & & & & & & \multirow{5}{*}{$12.121^{*}$} & \multirow{5}{*}{$0.047^{*}$} \\
\hline s1 year & 62 & 71.3 & 38 & 63.3 & 2 & 66.7 & & \\
\hline$>1$ to 5 years & 23 & 26.4 & 14 & 23.3 & 0 & 0.0 & & \\
\hline$>5$ to 10 years & 1 & 1.1 & 5 & 8.3 & 0 & 0.0 & & \\
\hline$>10$ to 20 years & 1 & 1.1 & 3 & 5.0 & 1 & 33.3 & & \\
\hline \multicolumn{9}{|l|}{ Manifestation of disease } \\
\hline Flu- like symptoms & 42 & 48.3 & 29 & 48.3 & 2 & 66.7 & 0.486 & 0.898 \\
\hline Bones pain & 79 & 90.8 & 52 & 86.7 & 3 & 100.0 & 0.808 & 0.594 \\
\hline Fever & 65 & 74.7 & 44 & 73.3 & 3 & 100.0 & 0.584 & 0.875 \\
\hline Night sweats & 13 & 14.9 & 11 & 18.3 & 1 & 33.3 & 1.470 & 0.454 \\
\hline \multicolumn{9}{|l|}{ Previous hospitalization } \\
\hline Yes & 19 & 21.8 & 8 & 13.3 & 0 & 0.0 & \multirow{2}{*}{1.872} & \multirow{2}{*}{0.377} \\
\hline No & 68 & 78.2 & 52 & 86.7 & 3 & 100.0 & & \\
\hline \multicolumn{9}{|c|}{ Patient's past surgical history } \\
\hline Previous surgery & & & & & & & & \\
\hline Yes & 7 & 8.0 & 5 & 8.3 & 0 & 0.0 & \multirow{2}{*}{0.268} & \multirow{2}{*}{1.000} \\
\hline No & 80 & 92.0 & 55 & 91.7 & 3 & 100.0 & & \\
\hline \multirow{2}{*}{\multicolumn{9}{|c|}{\begin{tabular}{|l} 
Family history \\
Leukemia
\end{tabular}}} \\
\hline Leukemia & & & & & & & & \\
\hline Yes & 13 & 14.9 & 8 & 13.3 & 0 & 0.0 & \multirow{2}{*}{0.210} & \multirow{2}{*}{0.883} \\
\hline No & 74 & 85.1 & 52 & 86.7 & 3 & 100.0 & & \\
\hline \multicolumn{9}{|c|}{$\begin{array}{l}\text { Other Autoimmune or cancer } \\
\text { disorders }\end{array}$} \\
\hline Yes & 34 & 39.1 & 20 & 33.3 & 1 & 33.3 & \multirow{2}{*}{0.660} & \multirow{2}{*}{0.767} \\
\hline No & 53 & 60.9 & 40 & 66.7 & 2 & 66.7 & & \\
\hline
\end{tabular}




\begin{tabular}{|c|c|c|c|c|c|c|c|c|}
\hline \multirow{3}{*}{ Clinical data } & \multicolumn{6}{|c|}{ Overall quality of life } & \multirow{3}{*}{$\chi^{2}$} & \multirow{3}{*}{${ }^{M C} \mathbf{p}$} \\
\hline & \multicolumn{2}{|c|}{$\begin{array}{c}\text { Poor } \\
(\mathbf{n}=87)\end{array}$} & \multicolumn{2}{|c|}{$\begin{array}{c}\text { Fair } \\
(n=60)\end{array}$} & \multicolumn{2}{|c|}{$\begin{array}{c}\text { Good } \\
(\mathbf{n}=3)\end{array}$} & & \\
\hline & No. & $\%$ & No. & $\%$ & No. & $\%$ & & \\
\hline \multicolumn{9}{|l|}{ Prescribed medication } \\
\hline Analgesics & 48 & 55.2 & 32 & 53.3 & 1 & 33.3 & 0.665 & 0.748 \\
\hline Antibiotics & 4 & 4.6 & 2 & 3.3 & 0 & 0.0 & 0.773 & 1.000 \\
\hline Immunosuppressive drugs & 5 & 5.7 & 6 & 10.0 & 0 & 0.0 & 1.224 & 0.485 \\
\hline Interferon & 8 & 9.2 & 8 & 13.3 & 0 & 0.0 & 0.808 & 0.596 \\
\hline Other (Contrloc) & 75 & 86.2 & 50 & 83.3 & 2 & 66.7 & 1.571 & 0.441 \\
\hline \multicolumn{9}{|l|}{ Side effects of medication } \\
\hline Pain & 85 & 97.7 & 58 & 96.7 & 2 & 66.7 & 5.334 & 0.106 \\
\hline Fatigue & 87 & 100.0 & 60 & 100.0 & 3 & 100.0 & - & - \\
\hline Nausea / vomiting & 80 & 92.0 & 55 & 91.7 & 3 & 100.0 & 0.268 & 1.000 \\
\hline Hair loss & 87 & 100.0 & 60 & 100.0 & 3 & 100.0 & - & - \\
\hline Stomatitis & 87 & 100.0 & 60 & 100.0 & 3 & 100.0 & - & - \\
\hline Other (Headache) & 87 & 100.0 & 60 & 100.0 & 3 & 100.0 & - & - \\
\hline
\end{tabular}

Table (1): Illustrates frequency distribution of studied patients in relation to their socio demographic characteristics. Regarding patient's age, it can be noticed that approximately half $(40.7 \%)$ of the studied patients were in the age group of 50 to 60 years old, while about one quarter $(35.3 \%)$ were in the age group of 21 to less than 30 years old. In addition, the table shows that more than half (64.7\%) of patients were males. Also, the table reveals that the majority of the studied patients $68 \%$ are married. Concerning level of education, it is evident that $40.7 \%$ of the studied patients were illiterate, while only $8.7 \%$ of them have university education. Also, the table denoted that about half (49.4\%) of the studied patients were manual workers and $31.3 \%$ of them were not worked. As regards to area of residence, the table revealed that more than half (76\%) of the studied patients live in urban area. In addition, $81.3 \%$ of the patients had insufficient income per month, from patient's point of view.

Table (2): Shows mean standard deviations and test of significance among the studied patient's overall quality of life domains. Regards the general health, the table showed that the majority $(58.7 \%)$ of the studied patients had poor quality of life, about $40.6 \%$ had fair quality of life and only $0.7 \%$ had good quality of life with Mean \pm SD $41.69 \pm 19.81$. As regards pain assessment, the table revealed that the majority $(68 \%)$ of the studied patients their severe pain lead to poor quality of life, $30 \%$ had fair quality of life and only $2 \%$ had good quality of life with Mean \pm SD $34.17 \pm 24.18$. According to social Functioning, the table revealed that less than half $(48.7 \%)$ of the studied patients had poor quality of life, $48 \%$ had fair quality of life and only $3.3 \%$ had good quality of life with Mean \pm SD 38.0 \pm 25.98 . Also, Psychological well-being, the table revealed that less than half $(40 \%)$ of the studied patients had poor quality of life, $48.7 \%$ had fair quality of life and less than one quarter $11.3 \%$ had good quality of life with Mean \pm SD $48.10 \pm 25.05$. Concerning Energy / Fatigue, the table revealed that less than half $(40 \%)$ of the studied patients had poor quality of life, $48.7 \%$ had fair quality of life and less than one quarter $11.3 \%$ had good quality of life with Mean \pm SD 48.83 \pm 20.90. While, Role limitation due to emotional problems, the table revealed that $41.3 \%$ of the studied patients had poor quality of life, and about more than half $(55.3 \%)$ had fair quality of life and only 3.3\% had good quality of life with Mean \pm SD $43.61 \pm$ 22.69). As regarding Role limitation due to physical health problems, the table revealed that less than half $(42.7 \%)$ of the studied patients had poor quality of life, and about more than half $(52.7 \%)$ had fair quality of life and only $4.7 \%$ had good quality of life with Mean \pm SD $45.25 \pm 23.11$. The same table revealed that less than half $(42.7 \%)$ of the studied patients had poor quality of life, $30 \%$ had fair quality of life and about one quarter $(27.3 \%)$ had good quality of life regarding physical functioning with Mean \pm SD $47.27 \pm 35.87$. Concerning overall quality of life domains, the table revealed that more than half $(58 \%)$ of the studied patients had poor quality of life in overall domains, while also, $40 \%$ had fair quality of life, and only $2 \%$ had good quality of life in overall domains. 
Table (3): Shows relationship between sociodemographic characteristics of the studied patients and overall QOL domains percent score. The table illustrated that there was no statistical significant relation between socio-demographic characteristics of the studied patients and quality of life domains, except in age, The table illustrated that, there was statistical relation between patient's age and QOL percentage score $\left({ }^{\mathbf{M C}} \mathbf{p}=\mathbf{0 . 0 2 4} *\right)$. The table illustrated that, more than one third $(37.9 \%)$ of patients reported poor QOL between age group 50-60 years , and noticed that the lowest percentage of the studied patients who had good QOL were aged between 21 30 years.

Table (4): Shows Relationship between clinical data of the studied patients and overall quality of life (QoL) domains percent score. The table illustrated that there was no statistical significant relation between clinical data of the studied patients and their QOL percentage score except patients' onset of disease. It was noticed that, the highest percentage of the studied patients who had onset of disease less than or equal one year reported poor QOL and there was statistical significant relation between the patient's onset of disease and overall QOL percentage score $\left({ }^{\mathrm{MC}} \mathbf{p}=\mathbf{0 . 0 4 7} *\right)$.

\section{Discussion:}

Leukemia is a serious health disease and one of the main causes of mortality in the world. It is estimated that it is going to be the eleventh cause of death (Terwilliger et al., 2017). This disease does not only influence patient's health, but also social relationships, life pattern, family atmosphere, occupation and income levels are influenced by it (Schumacher et al., 2015).

Quality of life (QOL) is considered an important aspect to be measured for patients with leukemia. Decline in QOL status is associated with greater mortality and rates of institutionalization. Therefore, this study was carried out to assess QOL in leukemia patients receiving chemotherapy in Alexandria Main University Hospital. Acarl, et al. (2015), who found that, more than half of the leukemia patients were females.

Concerning level of education, the result revealed that the majority of the patients were illiterate. This finding related to the fact that patients with low educational level tend to have poor awareness and knowledge about health-related issues and tend to present late, which increases morbidity. This result is supported by Gupta,et al., (2019) who mentioned that, most of their studied patients were of low educational level. Also, the study done by Irfan et al
(2013) who found that majority of patients were below high education. In relation to area of residence the findings revealed that the majority of the studied patients lived in urban area. This result may be related to the fact that bad lifestyle "smoking, exposure to benzene, synthetic fiber dust, radioactive materials, and toluene " are widely spread in urban societies than in rural area which affect negatively on the disease consequences. This finding is in some extent is similar to the study done by Apela, et al., (2016). However, these findings are contradicted with Neo et al., (2016) who found that the majority of their studied patients were from rural areas

As regards occupation, the study revealed that, most of the studied patients were manualy workers. This finding is in some extent are similar to Polychronakis et al. (2013) who stated that, most of the studied patients were manualy workers which confirmed the reason of incidence in males more than females due to exposure to different occupational hazards. Additionally, Talibov, et al,. 2012 mentioned that the majority of their studied patients were workers. However, this finding is controversial with Nurhayati, et al., (2019), who emphasized that, about one quarter of the study patients were not employee.

In relation to marital status, the present study found that the majority of the studied patients were married. This finding is in accordance with Zheng, et al., (2017) who mentioned that more than three quarters of the study patients were married. Also, Farsi, et al., 2010 emphasized that the majority of their studied patients were married. However, this result opposed Lemone, et al., (2014) who showed that half of their studied patients were single.

Concerning socioeconomic status the current study revealed that about three quarters of the patients had insufficient income as the reseacher openion, this results may be related to many factors; in which most of the study patients were manual worker and some of them were not working, also, most of them came from rural areas; all these factors contribute to the lower socioeconomic status of those patients and affect the overall health status. This finding is in accordance with Adler et al. (2012) who mentioned that most of their studied patients had low socioeconomic status. In relation to onset of disease, the result illustrated that more than half of the studied patients had leukemia since less than one year. It could be attributed to the fact that the incidence of leukemia increases with age and the majority of this study patients were between the ages of 50 to 60 years old. This result matched with Paffenbarger, et 
al. (2015), who mentioned that, most of their studied patients had diagnosis of leukemia in less than one year. On the other hand, this result is in contrast with Hirabayashi et al. (2014) who found that the most common onset in their studied patients were more than one year.

As regards patients' previous hospitalization and previous surgery, this current study revealed that, about three quarters of the studied patients had no previous hospitalization or previous surgery. The results were justified by the fact that some of the studied patients came from rural areas, where there is a lack of health awareness and periodic check-up. Also, there are delays in seeking medical care, which leads to decreased hospital visits and hospitalization. This result agrees with Tai, et al., (2017) who pointed that, most of their studied patients had no previous hospitalization or previous surgery. Also, agreed with Halpern, et al., (2017). However, these findings are contradicted with Zafar et al. (2013) who reported that most of their studied patients had previous surgery.

Concerning family history, the current study showed that, three quarters of the studied patients had family history of malignancy. This finding can be interpreted by the fact that family history of malignancy is considered as a risk factor for developing cancer in relatives; in which a family history of leukemia cancer increase the risk by three times in the firstdegree relatives, and in this study most of the patient had a medical diagnosis of leukemia. This finding is supported by Brown, Churpek, Döhner \& Godley (2017) who reported that about one third of the patients had at least one first or second-degree relative with a cancer diagnosis. In addition, Choi $\&$ Kim (2016) mentioned that the majority of their studied patients had a family history of leukemia .

Regarding general health of leukemia patients receiving chemotherapy, the present study portrayed that the majority of the studied patients had poor general health. This finding may be related to the fact of that the most of the studied patients' age from 5060 years old, complaint of chemotherapy related side effects and incapacity which could interfere negatively with all quality of life domains and the activities of daily living. This finding agreed with Redaelli, et al., (2014) who illustrated in similar study that the majority of the patients had poor general health. Also, Kurosawa et al (2015) mentioned that the majority of their studied patients had poor QOL.

Concerning pain assessment, the present study revealed that the majority of the leukemia patients had experienced severe pain after chemotherapy cycle as a side-effect of chemotherapy. This finding related to the fact of injury to nerves that can result from chemotherapy which explained chemotherapyrelated pain and fatigue, which extremely interfered with the patient's normal work as in housework and outside house work. This result is in line with Miladinia, et al., (2015) who illustrated in similar study that the majority of the patients had complaint of pain after chemotherapy ranged from slight to moderate feeling of pain when the remainders their feeling of pain was severe pain.

Pain has potentially negative effects on health status including extended length of hospitalization, increased hospital readmissions, delayed return of physical activity and lowered patient satisfaction and poor QOL (Miladinia, 2015). In this study, it was found that all of the studied patients had a chief complaint of pain and fatigue. These findings were associated with that the pain management still not optimal because lack of knowledge from both patients and the health care providers is considered as a main barrier for effective pain management, while the complaint of fatigue among the patients was related to that the body tries to repair the damage to healthy cells and tissue after chemotherapy. Consequently, patients felt tired due to the lack of energy.

This was in line with Miladinia et al., (2015) who illustrated in similar study that the majority of the patients had complaint of severe pain after chemotherapy. Furthermore, Alibhai et al., 2017 revealed that pain and fatigue were the most frequent complaint after chemotherapy in their studied patients. Not only these complaints, but also nausea, vomiting and hair loss were prominent. However, these results contradict the results of Chang et al (2018) who indicated that in their study of chemotherapy related side effects as pain and fatigue incidence occurring of these symptoms within the first several days and weeks after chemotherapy.

As regards, relation between overall quality of life domains and socio-demographic characteristics in leukemia patients after chemotherapy, the current study findings showed that a significant positive relationship was found between overall QOL dimensions and patients' age in which older adults who aged between 50-60 years old more vulnerable to poor QOL. This finding can be justified by the fact that the adaptive capacity of individuals is gradually decreases with age, especially before and after major life events like repeated hospitalization and some of the studied patients from rural areas and insufficient income which making them vulnerable to reduced 
physical functioning, psychological and social participation.

This result is in accordance with study done by Kantarjian et al. (2010) who illustrated that patient's age is a multifactorial demographic characteristic which younger patients had better physical activity and prognosis better than older patients after chemotherapy. Moreover, study done by Petersdorf et al., 2016 pointed that younger patients who aged between 20-35 years showed significant improvement in their quality of life than older patients approximately two cycles of chemotherapy and prolonged remission period.

Regarding, relationship between QOL dimensions with clinical data, the current study revealed that a significant relationship was found between overall QOL and onset of the disease, in which the studied patients who had onset of disease less than one year had poor QOL. This finding is associated with fact of that some of patients were older age, fear of death and anxiety from disease consequences, and sudden hospitalization. These results were agreed with Matsuoka M (2015) who concluded in a similar study that some of the studied patients had poor QOL regarding onset of disease in while it's occurrence less than one year. On other hand, a study done by Gotay et al., (2018) \& (Messerer et al; 2018) who pointed that the prognosis and impact of remission strategies of the disease was better after the early diagnosis which the onset of disease less than one year.

So, it can be concluded that treatment with chemotherapy has negative consequences that can affect quality of life of the receiver of it over all their aspects of health and life. Hence, health care team must provide patient receiving chemotherapy with individualized, comprehensive care to facilitate physical, psychological, rehabilitation and promote quality of life.

\section{Conclusion}

Based on the findings of the present study, it can be concluded that patients with leukemia who received chemotherapy had poor QOL which have negative impact on patient's physical, psychological, social life, and spiritual life.

Moreover, severe pain and complications after chemotherapy that interferes with movement, walking and usual activities.

\section{Recommendations:}

- Development and application of educational sessions for patients and their families to improve their knowledge about chemotherapy and how to deal and cope with those side- effects.

- Training and educational programs need to be implemented for nurses at chemotherapy unit which working with leukemia patients before and during receiving chemotherapy about self-care strategies to manage side-effects of chemotherapy.

- Study of the effect of implementing self-care strategies in improving quality of life in leukemia patients receiving chemotherapy.

\section{References:}

- Altieri, A., Chen, B., Bermejo, J., Castro, F., \& Hemminki, K. (2016): Familial risks and temporal incidence trends of multiple myeloma. European journal of cancer, 42(11), 1661-1670.

- Acarl, S., Gözmen, S., Bayraktaroglu, T., Karapinar, Y., Ay, Y., Oymak, B., Demirag1, D., Ince1, G., Özek, Y., \& Aydinok, C .(2015): Vergin1 Hematology- Oncology, Dr. Behçet Uz Hospital, Izmir, Turkey 39(8), 389- 394.

- Apela, N., Nzayisenga, I., Sethi, R., Bigirimana, J., Habineza, H., Hategekimana, V., Mantini, N., Mpunga, T., Shulman, L., \& Lehmann, L. (2016): Treatment of Chronic Myeloid Leukemia in Rural Rwanda: Promising Early Outcomes. Journal of global oncology, 2(3), 129-137

- Alibhai, S., Leach, M., Kowgier, M., Tomlinson, G., Brandwein, J., \& Minden, M. (2017): Fatigue in older adults with acute myeloid leukemia: predictors and associations with quality of life and functional status. Leukemia, 21(4), 845-848.

- Adler, N., \& Newman, K. (2012): Socioeconomic disparities in health: pathways and policies. Health affairs, 21(2), 60-76.

- Brown, A., Churpek, J., Malcovati, L., Döhner, H., \& Godley, L. (2017): Recognition of familial myeloid neoplasia in adults. In Seminars in hematology (Vol. 54, No. 2, pp. 60-68). WB Saunders

- Choi, Y., \& Kim, N. (2016): Cancer and family history. The Korean journal of internal medicine, 31(6), 1042-1053.

- Chang, P., Lai, Y., Shun, S., Lin, L., Chen, M., Yang, Y., \& Cheng, S. (2018): Effects of a walking intervention on fatigue-related experiences of hospitalized acute myelogenous leukemia patients undergoing chemotherapy: a randomized controlled trial. Journal of pain and symptom management, 35(5), 524-534.

- Curado, M., Edwards, B., Shin, H., Storm, H., 
Ferlay, J., Heanue, M., \& Boyle, P. (2017): Cancer Incidence in Five Continents Volume IX. Lyon, France: IARC Scientific Publication35 (4), $15-23$.

- DeSantis CE, Lin CC, \& Mariotto AB. (2014): Cancer treatment and survivorship statistics, 2014. CA: a cancer journal for cliniciansVOl. (64)No.(5),Pp.252- 271.

- El-desouky, E., Noaman, M., Shalaby, L., \& Shaaban, S. (2017): Factors Affecting Quality of Life in Patients with Pediatric Leukemia during Induction Chemotherapy. The Egyptian Journal of Community Medicine, 35(4), 15-23.

- Farsi, Z., Dehghan N., \& Negarandeh, R. (2010): Coping strategies of adults with leukemia undergoing hematopoietic stem cell transplantation in Iran: a qualitative study. Nursing \& health sciences, 12(4), 485-492.

- Gupta, S., Bonilla, M., \& Fuentes, S. (2019): Incidence and predictors of treatment- related mortality in acute leukaemia in El Salvador. British Journal Cancer 100, 1026-1031.

- Gotay, C., \& Muraoka, M. (2018): Quality of life in long-term survivors of adult-onset cancers. JNCI: Journal of the National Cancer Institute, Vol. (90).No. (9), Pp. 656-667.

- Ghazawi, F., Le, M., Cyr, J., Netchiporouk, E., Rahme, E., Alakel, A., \& Glassman, S. (2019): Analysis of acute myeloid leukemia incidence and geographic distribution in Canada from 1992 to 2010 reveals disease clusters in Sarnia and other industrial US border cities in Ontario. Cancer, 125(11), 1886-1897.

- Hallek, M. (2015): Chronic lymphocytic leukemia: 2015 Update on diagnosis, risk stratification, and treatment. American journal of hematology, Vol. (90).No. (5), Pp. 446-460.

- Hirabayashi, Y., Yoon, B., Li, G., Kanno, J., \& Inoue, T. (2014): Mechanism of benzene-induced hematotoxicity and leukemogenicity: current review with implication of microarray analyses. Toxicologic pathology, 32(2_suppl), 12-16

- Halpern, A., Culakova, E., Walter, R., \& Lyman, G. (2017): Association of risk factors, mortality, and care costs of adults with acute myeloid leukemia with admission to the intensive care unit. JAMA oncology, 3(3), 374-381

- Huang, C., Ju, D., Chang, C., Muralidhar Reddy, P., \& Velmurugan, B. (2017): A review on the effects of current chemotherapy drugs and natural agents in treating non-small cell lung cancer. BioMedicine, 7(4), 23. https://doi.org/10.1051/bmdcn/ 2017070423

- Irfan SMN, Rahaman M., Noman A., \&
Mithun S. (2013): Health Related Quality of Life Among Coronary Artery Bypass Graft Patient Attended at Combined Military Hospital, Dhaka. AKMMC Journal; 4(2): 10- 7.

- Kebriaei, P., de Lima, M., Estey, E., \& Champlin, R. (2015): Management of Acute Leukemias. In V. T. DeVita, T. S. Lawrence \& S. A. Rosenberg (Eds.), DeVita, Hellman, and Rosenberg's Cancer: Principles and Practice of Oncology (10th ed p.p. 1615-1636). Philadelphia: Lippincott Williams \& Wilkins.

- Kasim, K., Levallois, P., Abdous, B., Auger, P., \& Johnson, K. (2015): Lifestyle factors and the risk of adult leukemia in Canada. Cancer causes \& control, 16(5), 489-500.

- Kurosawa, S., Yamaguchi, T., Mori, T., Kanamori, H., Onishi, Y., Emi, N., \& Kondo, T. (2015): Patient-reported quality of life after allogeneic hematopoietic cell transplantation or chemotherapy for acute leukemia. Bone marrow transplantation, 50(9), 1241-1249.

- Kantarjian, H., Ravandi, F., O'Brien, S., Cortes, J., Faderl, S., Garcia-Manero, G., \& Shan, J. (2010): Intensive chemotherapy does not benefit most older patients (age 70 years or older) with acute myeloid leukemia. Blood, The Journal of the American Society of Hematology, 116(22), $4422-4429$.

study done by petersdorf et al., 2016

- Lemone, P., Burke, K., Levett-Jones, T., Dwyer, T., Moxham, L., Reid-Searl, K., \& Raymond, D. (2014): Medical-surgical nursing: critical thinking for person-centred care (2nd ed p.p. 671-791). Midland Typesetters: Australia:Pearson Australia.

- Larson, R., Hochhaus, A., Hughes, T., Clark, R., Etienne, G., Kim, D., \& Blakesley, R. (2012): Nilotinib vs imatinib in patients with newly diagnosed Philadelphia chromosomepositive chronic myeloid leukemia in chronic phase: ENESTnd 3-year followup. Leukemia, 26(10), 2197-2203.

- Miladinia, M., Baraz, S., Shariati, A., Malehi, A., \& Amadzadeh, A. (2015): Relationship between chronic pain and quality of life in patients with acute leukemia undergoing chemotherapy. Jundishapur Journal of Chronic Disease Care, 4(3).

- Matsuoka, M. (2015): Human T-cell leukemia virus type I (HTLV-I) infection and the onset of adult T-cell leukemia (ATL). Retrovirology, Vol. (2),No.(1),Pp. 27.

- Mains, F.H \& Andaleeb, S.S. (2016): Service quality perceptions and client satisfaction: A 
study of hospitals in a developing country (4th ed ). Pp. 1359-1370.

- Messerer, D., Engel, J., Hasford, J., Schaich, M., Ehninger, G., Sauerland, C., \& Krauter, J. (2018): Impact of different post-remission strategies on quality of life in patients with acute myeloid leukemia. haematologica, 93(6), 826833.

- Neo Tapela, Ignace Nzayisenga, Roshan Sethi, Jean Bosco Bigirimana, Hamissy Habineza, Vedaste Hategekimana, Nicholas Mantini, Tharcisse Mpunga, Lawrence N. Shulman, and Leslie Lehmann.(2016) Treatment of Chronic Myeloid Leukemia in Rural Rwanda: Promising Early Outcomes. 2016 Journal of Global Oncology 2:3, 129-137

- Nurhayati, N., Songwathana, P., \& Vachprasit, R. (2019): Surgical patients' experiences of readiness for hospital discharge and perceived quality of discharge teaching in acute care hospitals. Journal of clinical nursing, 28(9-10), 1728-1736.

- Paffenbarger Jr, R., Wing, A., \& Hyde, R. (2015): Characteristics in youth predictive of adult-onset malignant lymphomas, melanomas, and leukemias: Brief Communications. Journal of the National Cancer Institute, 60(1), 89-92

- Porcu, P., Cripe, L., Ng, E., Bhatia, S., Danielson, C., Orazi, A., \& McCarthy, L., (2016): Hyperleukocytic leukemias and leukostasis: a review of pathophysiology, clinical presentation and management. Leukemia \& lymphoma, 39(1-2), 1-18.

- Polychronakis, I., Dounias, G., Makropoulos, V., Riza, E., \& Linos, A. (2013): Work- related leukemia: a systematic review. Journal of occupational medicine and toxicology (London, England), 8(1), 14.

- Robison, L. (2012): Down syndrome and leukemia. Leukemia, Vol. (6 Suppl), No. (1), Pp. 5-7.

- Redaelli, A., Stephens, J., Laskin, B., Pashos, C., \& Botteman, M. (2013): The burden and outcomes associated with four leukemias: AML, ALL, CLL and CML. Expert review of anticancer therapy, 3(3), 311-329.

- Redaelli, A., Stephens, J., Brandt, S., Botteman, M., \& Pashos, C. (2014): Short-and long-term effects of acute myeloid leukemia on patient health-related quality of life. Cancer treatment reviews, 30(1), 103-117.

- Stiller, C., Chessells, J., \& Fitchett, M. (2014):
Neurofibromatosis and childhood leukaemia/ lymphoma: a population-based UKCCSG study. British journal of cancer, 70(5), 969-972.

- Schumacher, A., Kessler, T., Büchner, T., Wewers, D., \& Van De Loo, J. (2015): Quality of life in adult patients with acute myeloid leukemia receiving intensive and prolonged chemotherapy. Leukemia, 12(4), 586-592

- Schirrmacher V. (2019): From chemotherapy to biological therapy: A review of novel concepts to reduce the side effects of systemic cancer treatment (Review). International journal of oncology, 54(2), 407-419. https://doi.org/10.3892/ijo.2018.4661

- Talibov, M., Kautiainen, S., Martinsen, J., Kjaerheim, K., Lynge, E., Sparen, P., Tryggvadottir, L., Weiderpass, Eete; Pukkala \& Eero. (2012): Journal of Occupational and Environmental Medicine 54(12), 1527-1532

- Tai, E., Guy, G., Dunbar, A., \& Richardson, L. C. (2017): Cost of cancer-related neutropenia or fever hospitalizations, United States, 2012. Journal of oncology practice, 13(6), e552-e561

- Terwilliger, T., \& Abdul-Hay, M. (2017): Acute lymphoblastic leukemia: a comprehensive review and 2017 update. Blood cancer journal, Vol. (7), No. (6), Pp.577

- World Health Organization (2012): Division of mental health and prevention of substance abuse .

- Ware, J. (2014): Overview of the SF-36 Health Survey and the International Quality of Life Assessment (IQOLA) Project. Journal of clinical epidemiology, 51(11), 903-912.

- Zafar, S., Fatmi, Z., Iqbal, A., Channa, R., \& Haider, A. (2013): Disparities in access to surgical care within a lower income country: an alarming inequity. World journal of surgery, 37(7), 1470-1477.

- Zheng, Z., Zhu, Y., Li, X., Hu, W., \& Jiang, J. (2017): Impact of marital status during diagnosis on cancer-caused specific survival in acute myeloid leukemia patients: a case-control and population-based study. Oncotarget, 8(37), 62666. 